\title{
Familial Mediterranean Fever: Clinical and Genetic Characteristics among Lebanese Pediatric Population
}

\author{
Sirine Mneimneh1, Amal Naous ${ }^{1 *}$, Ziad Naja1 ${ }^{1}$, Zeina Naja ${ }^{1}$, Ahmad Salaheddine Naja1, \\ Andre Megarbane'2, Mariam Rajab ${ }^{1}$ \\ ${ }^{1}$ Department of Pediatrics, Makassed General Hospital, Beirut, Lebanon \\ ${ }^{2}$ Institut Jerome Lejeune, Paris, France \\ Email: "amalnaous@hotmail.com
}

Received 20 February 2016; accepted 12 August 2016; published 15 August 2016

Copyright (C) 2016 by authors and Scientific Research Publishing Inc.

This work is licensed under the Creative Commons Attribution International License (CC BY). http://creativecommons.org/licenses/by/4.0/

(c) (i) Open Access

\begin{abstract}
Objective: The aim of our study was to evaluate the clinical features, to define the frequency of mutation type, to assess genotype-phenotype correlation and the response to colchicine in childhood-onset Familial Mediterranean fever (FMF) in Lebanon. Methods: The characteristics of 550 children, presenting with FMF symptoms between January 2003 and January 2013 and having a positive Mediterranean fever gene (MEFV gene) mutation, were prospectively investigated. The clinical and genetic characteristics as well as the response to colchicine and its side effects were studied in 321 FMF children. The mutations were correlated with clinical presentation and disease severity. Results: Out of the 321 patients (183 males and 138 females), abdominal pain was the most common presenting feature documented in $84.7 \%$. Mutational analysis detected simple heterozygotes, compound heterozygotes and homozygotes in $56.4 \%, 30.9 \%$ and $11.2 \%$ patients respectively. The most frequent mutation was M694V (37.2\%), followed by E148Q mutation (27.4\%). $71 \%$ patients received colchicine therapy; only $33.3 \%$ of them showed complete response. Genotype-phenotype correlation showed that $\mathrm{M694V}$ followed by E148Q was associated with moderate to severe disease form $(71.6 \%$ and $62.7 \%$ respectively, $P=0.005)$. There was no association between mutation type and colchicine response. Conclusion: The most important features were the predominance of the M694V and E148Q. The M694V subgroup, followed by E148Q subgroup had a high disease severity score. Our data indicate an enhanced expression of the disease with E148Q mutation.
\end{abstract}

\section{Keywords}

Familial Mediterranean Fever, MEFV Gene Mutation, Colchicine

\footnotetext{
${ }^{*}$ Corresponding author.
}

How to cite this paper: Mneimneh, S., Naous, A., Naja, Z., Naja, Z., Naja, A.S., Megarbane, A. and Rajab, M. (2016) Familial Mediterranean Fever: Clinical and Genetic Characteristics among Lebanese Pediatric Population. Open Journal of Rheumatology and Autoimmune Diseases, 6, 63-73. http://dx.doi.org/10.4236/ojra.2016.63011 


\section{Introduction}

Familial Mediterranean fever (FMF) is the most frequent periodic syndrome characterized by self-limited recurrent attacks of fever and serositis. It is an autosomal-recessive disorder that predominantly affects people from the Mediterranean region, including Sephardic Jews, Turks, Armenians, and Arabs [1]. FMF is caused by mutations in the Mediterranean fever (MEFV) gene, which is located on the short (p) arm of chromosome 16 at position 13.3. The gene encodes a protein called pyrin/maronestrin that regulates neutrophil activity [2].

Five founding mutations M694V, V726A, M680I, M694I (in exon 10), and E148Q (in exon 2) are the most common MEFV mutations [3].

FMF is diagnosed mainly by clinical criteria based on Tel Hashomer criteria for the diagnosis of FMF [4] (Table 1). Genetic analysis is used to confirm the diagnosis and is especially helpful in oligosymptomatic patients [5]. Phenotype and genotype correlation in FMF has not been explained definitely [6]. The most devastating complication of FMF is AA-type amyloidosis with prominent renal involvement. Colchicine is the mainstay of FMF treatment; it can prevent attacks, amyloid deposition, and mortality from this complication.

There are limited data regarding the features of FMF in Lebanon, particularly among children.

The objectives of the present study are as follows: i) to review clinical and demographic features of patients with childhood-onset FMF in Lebanon, ii) to evaluate the frequency of most common mutations of FMF gene, iii) to investigate whether there is phenotype-genotype correlation in this population, and iv) to identify any adverse effects of colchicine in pediatric patients with FMF.

\section{Materials and Methods}

The pediatric cohort study group included five hundred fifty FMF Lebanese children with positive MEFV gene mutation. Patients included in the study aged 18 years or younger and referred with FMF symptoms, from various pediatric clinics to the Laboratory Department of genetic testing at Saint-Josef University, between January 2003 and January 2013, were included in the study. All of them had at least one MEFV gene mutation. The study was approved by the Institutional Review Board at Makassed General Hospital, Beirut, Lebanon, and all children with their caregivers gave informed consent to the study.

The criteria to include patients were: 1) age at FMF diagnosis $\leq 18$ years, 2) with at least one $M E F V$ gene mutation, 3) presenting with short attacks of fever at varying intervals or painful sensation in the abdomen, chest and joint or with skin manifestations, with absence of any pathological finding capable in itself explaining the clinical picture and 4) being of Lebanese nationality.

The demographic and clinical characteristics, results of $M E F V$ gene mutation analysis were recorded and analyzed. Baseline characteristics including age, gender, date of birth, country of origin, religion, parental consanguinity, family history of FMF or renal amyloidosis, affected relatives with FMF, age of onset of disease and age at diagnosis were all determined. Clinical manifestations including features such as duration and frequency of fever, abdominal pain, arthralgia, chest pain, headache, vomiting, diarrhea, constipation, myalgia, cutaneous manifestations, liver involvement, number of the attacks, previous hospitalizations and surgeries done prior to diagnosis were also determined for the study.

The efficiency of colchicine in suppressing the attacks, including colchicine doses, possible side effects and number of FMF attacks after colchicine treatment, were all evaluated. Response to colchicine treatment was

Table 1. Tel Hashomer criteria for the diagnosis of FMF.

\begin{tabular}{|c|}
\hline Major Criteria \\
\hline $\begin{array}{l}\text { 1. Recurrent febrile episodes accompanied by peritonitis, synovitis or pleuritis } \\
\text { 2. Amyloidosis of the AA type without predisposing disease } \\
\text { 3. Favorable response to continuous colchicine treatment }\end{array}$ \\
\hline Minor Criteria \\
\hline $\begin{array}{l}\text { 1. Recurrent febrile episodes } \\
\text { 2. Erysipelas-like erythema } \\
\text { 3. FMF in a first-degree relative }\end{array}$ \\
\hline $\begin{array}{l}\text { Definite diagnosis: } 2 \text { major or } 1 \text { major and } 2 \text { minor criteria } \\
\text { Probable diagnosis: } 1 \text { major and } 1 \text { minor criteria }\end{array}$ \\
\hline
\end{tabular}


evaluated as complete response defined as complete control of the clinical manifestations, incomplete (decline > $50 \%$ in the frequency of attacks) and unresponsive (no improvement in frequency attack and/or severity of the disease despite colchicine treatment).

To assess the severity of the disease, we used a disease severity score adapted by Ozen et al. A total score of 3-5 is accepted as mild, 6-9 is moderate and above 9 is severe disease [7] (Table 2).

For specified evaluation of phenotype-genotype correlation, the patients underwent three different types of classifications. First, the patients were classified according to M694V gene mutation into three groups: Group I, M694V/M694V; Group II, M694V/other; and Group III, other/other. Second, the patients were classified according to the genotypes with one or two mutations of M694V, E148Q, V726A group and others (other mutations).

The two classifications were compared in terms of age of onset, age at diagnosis, time interval between the disease onset and diagnosis, fever, abdominal pain, arthralgia, chest pain, severity of the disease and response to colchicine.

\subsection{The MEFV Gene Mutation Analysis}

Molecular diagnosis of FMF was carried out in the Laboratory Department for genetic testing at Saint-Josef University. $3 \mathrm{ml}$ of blood was withdrawn from each patient into tubes containing ethylenediamine-tetraacetic acid. DNA was extracted using a commercial kit; sequencing was performed for the analysis of the $M E F V$ gene. $M E F V$ gene at exons 2, 3, 5, 10 was screened for the causative mutations, approximately for more than 30 mutations (Figure 1). PCR products from genomic DNA were purified using the illustra TM GFX PCR DNA and Gel Band Purification Kit (GE Healthcare, Buckinghamshire, UK), and both strands of the resultant products were sequenced using the BigDye ${ }^{\circledR}$ Terminator v1.1 Cycle Sequencing Kit (Applied Biosystems, Foster City, CA) under standard conditions. The labeled products were subjected to electrophoresis on an ABI 3130 Genetic Analyzer sequencing system (Applied Biosystems, Foster City, CA, USA). Electropherograms were analyzed using Sequence Analysis Software version 5.2 (Applied Biosystems, Foster City, CA, USA) and compared to reference sequences using ChromasPro version 1.7.5.4 (Technelysium, Queensland, Australia).

Table 2. Modified severity score for children by Ozen et al. [7].

\begin{tabular}{ccc}
\hline Parameter & Features & Score \\
\hline Age of onset (years) & $11-20$ & 2 \\
& $6-10$ & 4 \\
Number of attacks per month & $<6$ & 1 \\
& $1-2$ & 3 \\
Arthritis & Acute & 2 \\
Erysipelas-like erythema & Protracted & 3 \\
Amyloidosis & 3. & 2 \\
Dose of colchicine & Less than appropriate dose & 3 \\
& Appropriate dose & \\
& More than appropriate dose & 2 \\
\hline
\end{tabular}

A total score of 3 - 5 is accepted as mild, 6 - 9 is moderate and $>9$ is severe disease. "Starting colchicine doses for children with familial Mediterranean fever: $<5$ years, $0.5 \mathrm{mg} /$ day; 5 - 10 years, $1.0 \mathrm{mg} /$ day; $>10$ years, $1.5 \mathrm{mg} /$ day. 


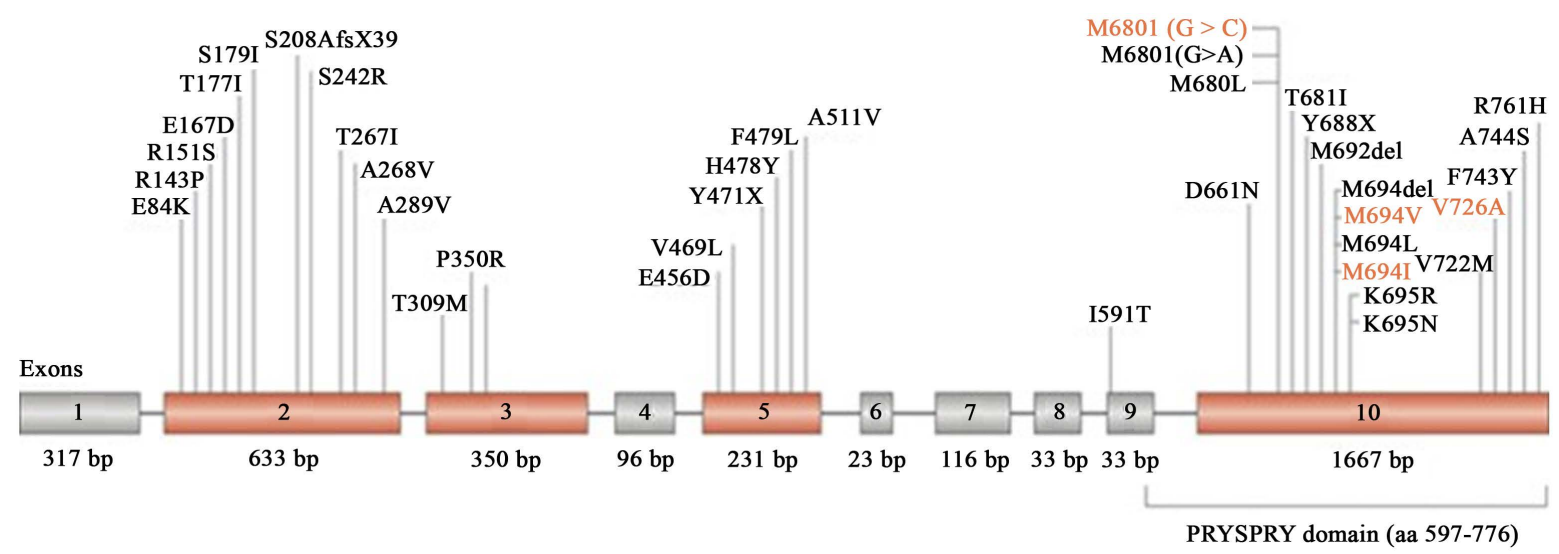

Figure 1. Schematic representation of recessively inherited FMF-associated mutations in the MEFV gene.

\subsection{Statistical Analysis}

All the analyses were performed using SPSS version 19. The data were presented as mean \pm SD or number (percent). One Way ANOVA and Chi-square test were utilized to assess significance differences among the groups. Nonparametric test (goodness of fit) was used to compare the results of this study with those of other studies. $P$-value $<0.05$ was considered significant.

\section{Results}

The study population was composed of a total of 550 FMF Lebanese children; all were included in the MEFV mutational analysis. However, only 321 children with FMF were included in the analysis of demographic and clinical characteristics, use of colchicine and phenotype-genotype correlation. The remaining 229 children with FMF were excluded from the above analysis due to lack of clinical information or incomplete chart data.

Genetic data: Table 3 demonstrates the MEFV mutations that were detected in 550 FMF children, of whom 310 (56.4\%) were simple heterozygotes, 170 (30.9\%) were compound heterozygotes, 62 (11.2\%) were homozygotes and 8 (1.5\%) were complex heterozygotes. Regarding frequency of each identified MEFV mutation, M694V was found to be the most common mutation and was detected in 205/550 (37.2\%). E148Q was the second most common mutation and was detected in 151/550 (27.4\%), followed by V726A in 139/550 (25.3\%), then M680I in 96/550 (17.4\%) and then M694I in 84/550 (15.3\%) of children with FMF.

Clinical data: Of the 321 children with FMF, 183 (57\%) were males and 138 (43\%) were females (male/ female ratio 1.1:1).The mean age of onset $4.61 \pm 3.76$ years (range from 1 month to 16 years of age).The mean age at diagnosis onset was $7.08 \pm 4.24$ years. The mean delay in diagnosis of FMF in Lebanese children was $2.63 \pm 2.08$ years. When the data were analyzed with regard to child's parental region of origin and religion, $44.9 \%$ had originated from South Lebanon, followed by North Lebanon (25.5\%) and then from the capital Beirut (19.3\%). Regarding the religion, it was noticed that $83.2 \%$ of FMF children were Moslems and $16.2 \%$ were Christians. Consanguinity rate was $11.5 \%$ in the families of the children with FMF. Family history of FMF was noticed in $40.8 \%$. Family history of renal amyloidosis was noted only in $2(0.6 \%)$ children with FMF.

The main clinical characteristics of the patients were as follow : Abdominal pain was the most common form of presentation (84.7\%), followed by fever (78.2\%). 40.8\% of children with FMF had attack frequency of one or two attacks per month, and most of the patients (94.7\%) had attack duration less than 5 days. Eight patients (2.5\%) underwent appendectomy prior to the diagnosis. 144 patients with FMF (44.9\%) were hospitalized, and in most cases (88.2\%), 1-3 times prior the diagnosis of FMF. None of the 321 patients studied developed renal amyloidosis over the period of follow up. The distribution of FMF disease severity score was as follows: mild disease (a score $=3-5)$ in $132(41.1 \%)$, moderate (a score $=6-9)$ in $187(58.3 \%)$ and severe (a score $>9)$ in 2 (0.6\%) (Table 4).

Response to colchicine treatment

Of the 321 patients, 228 (71\%) patients were treated with colchicine. Regarding the colchicine dosage for age, we found that 148 (64.9\%) patients were receiving colchicine dose less than appropriate for age, and only 68 (29.8\%) patients were receiving the appropriate dose for age, whereas, 12 (5.3\%) patients were receiving colchi- 
Table 3. Genotypes of Lebanese children with FMF: homozygotes, compound heterozygotes, simple heterozygotes and complex heterozygotes.

\begin{tabular}{|c|c|c|}
\hline Mutations & Genotype & Patients, n (\%) \\
\hline \multirow{7}{*}{ Homozygotes } & & $62(11.2 \%)$ \\
\hline & M694V/M694V & 28 \\
\hline & M694I/M694I & 13 \\
\hline & E148Q/E148Q & 9 \\
\hline & V726A/V726A & 9 \\
\hline & M680I/M680I & 2 \\
\hline & R761H/R761H & 1 \\
\hline \multirow[t]{16}{*}{ Compound heterozygotes } & & $170(30.9 \%)$ \\
\hline & M694V/V726A & 35 \\
\hline & E148Q/M694V & 12 \\
\hline & M694V/M694I & 12 \\
\hline & M694I/V726A & 11 \\
\hline & M680I/V726A & 10 \\
\hline & M694V/R761H & 8 \\
\hline & E148Q/M694I & 8 \\
\hline & E148Q/V726A & 8 \\
\hline & M680I/M694V & 7 \\
\hline & M694I/R761H & 6 \\
\hline & M694V/E148Q & 3 \\
\hline & P369S/R408Q & 3 \\
\hline & E474K/R761H & 3 \\
\hline & E167D/F479L & 3 \\
\hline & Others & 41 \\
\hline \multirow[t]{10}{*}{ Simple heterozygotes } & & $310(56.4 \%)$ \\
\hline & E148Q/- & 92 \\
\hline & M694V/- & 68 \\
\hline & V726A/- & 52 \\
\hline & M694I/- & 32 \\
\hline & A744S/- & 21 \\
\hline & $\mathrm{R} 761 \mathrm{H} /-$ & 9 \\
\hline & A289V/- & 7 \\
\hline & I259V/- & 4 \\
\hline & Others & 25 \\
\hline \multirow[t]{8}{*}{ Complex heterozygotes } & & $8(1.5 \%)$ \\
\hline & P369S/R408Q/A457V & 2 \\
\hline & V726Z/R7261H/E148Q & 1 \\
\hline & P369S/R408Q/R761H & 1 \\
\hline & E148Q/E148V/M694I & 1 \\
\hline & E167D/F479L/V726A & 1 \\
\hline & I692del/E148Q/E148V & 1 \\
\hline & P369S/R408S/V726A & 1 \\
\hline Total & & 550 \\
\hline
\end{tabular}

Table 4. Clinical characteristics of 321 FMF children.

\begin{tabular}{cc}
\hline Signs and symptoms & Patients, n (\%) (n = 321) \\
\hline Abdominal pain & $272(84.7 \%)$ \\
Fever & $251(78.2 \%)$ \\
Arthralgia & $138(43 \%)$ \\
Chest pain & $98(30.5 \%)$ \\
\hline
\end{tabular}




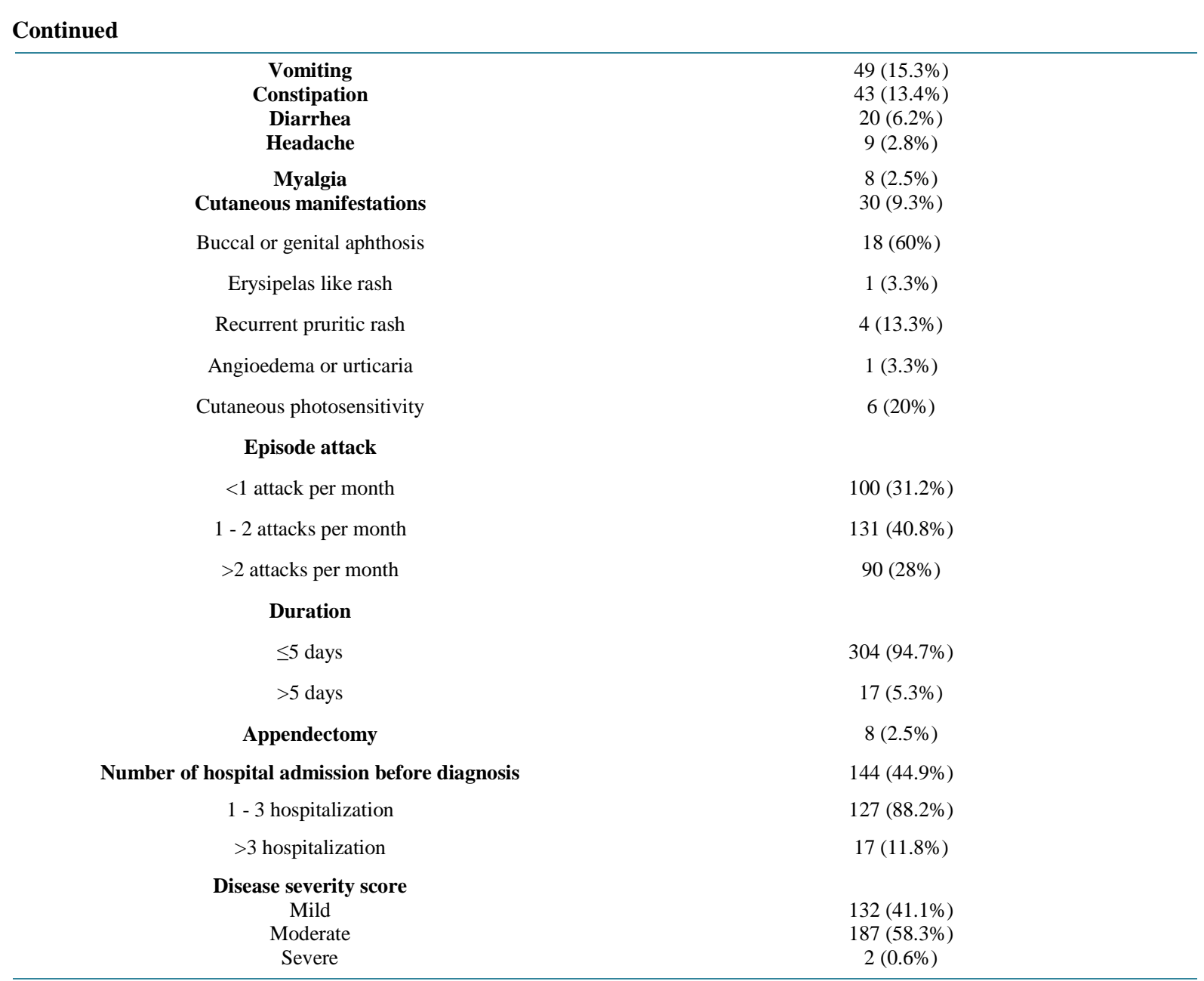

cine dose more than required for age. 76 (33.3\%) patients on colchicine responded with complete remission, whereas, 119 (52.2\%) patients showed incomplete response and 33 (14.5\%) patients did not show any response to colchicine.

Colchicine was well tolerated by most of our patients. Only 64 (28\%) of FMF patients treated with colchicine developed adverse events. The most reported adverse effects was diarrhea in 28 (12.3\%) FMF patients treated with colchicine, headache in 17 (7.5\%), vomiting in 8 (3.5\%), rash in 5 (2.2\%), muscle weakness in $4(1.8 \%)$ and both thrombocytopenia and leucopenia were observed in one (0.4\%) patient only.

Genotype-phenotype correlation

Table 5 summarizes the distribution of phenotypic features according to the existence of the M694V mutation among the three groups. The age of onset of symptoms was earlier in both (M694V/M694V) and (M694V/other) groups in comparison with (other/other) group $(P=0.04)$. Regarding the clinical features, fever was significantly higher in both (M694V/M694V) and (M694V/other) groups in comparison with (other/other) group $(P=$ 0.018). Patients with homozygous M694V had higher rates of arthralgia and hospitalization prior to FMF diagnosis in comparison with the other groups $(P=0.032$ and $P=0.015$ respectively). Regarding severity score, patients homozygous for M694V had a higher severity score compared with other groups $(P=0.008)$. There was no statistically significant difference among the studied groups concerning response to colchicine treatment.

While the patients were divided into four subgroups according to genotypes of one or two mutations of M694V, E148Q, V726A and others, fever and chest pain were found to be more frequent in M694V and V726A subgroups when compared to other subgroups $(P=0.003$ and $P=0.007$ respectively).The M694V subgroup, followed by E148Q subgroup had higher disease severity score (moderate and severe), compared to other subgroups $(P=0.005)$. There was no statistically significant difference among the studied groups concerning response to colchicine treatment (Table 6). 
Table 5. Clinical features of subgroups according to the M694V mutation.

\begin{tabular}{ccccc}
\hline & M694V/M694V (n = 17) & M694V/Other $(\mathbf{n}=\mathbf{7 2})$ & Other/Other (n = 232) & P-value \\
\hline Age of onset (years), mean \pm SD & $3.9 \pm 2.7$ & $3.7 \pm 3.5$ & $4.9 \pm 3.7$ & 0.041 \\
Age at diagnosis (years), mean \pm SD & $6.4 \pm 3.7$ & $6.618 \pm 4.4$ & $7.2 \pm 4.2$ & 0.426 \\
Delay in diagnosis (years), mean \pm SD & $2.5 \pm 2.3$ & $2.9 \pm 2$ & $2.5 \pm 2$ & 0.592 \\
Abdominal pain & $15(88.2 \%)$ & $61(84.7 \%)$ & $196(84.5 \%)$ & 0.917 \\
Fever & $15(88.2 \%)$ & $64(88.9 \%)$ & $172(74.1 \%)$ & 0.018 \\
Chest pain & $7(41.2 \%)$ & $29(40.3 \%)$ & $62(26.7 \%)$ & 0.057 \\
Arthralgia & $12(70.6 \%)$ & $34(47.2 \%)$ & $92(39.7 \%)$ & 0.032 \\
$>3$ hospitalizations prior to diagnosis & $3(17.6 \%)$ & $1(1.4 \%)$ & $13(5.6 \%)$ & 0.015 \\
Response to colchicine & & & & 0.069 \\
No response & $2(11.8 \%)$ & $7(9.7 \%)$ & $47(20.3 \%)$ & $90(38.8 \%)$ \\
Incomplete response & $11(64.7 \%)$ & $36(50 \%)$ & $95(40.9 \%)$ & \\
Complete response & $4(23.5 \%)$ & $9(40.3 \%)$ & & 0.008 \\
Severity score & & & $107(46.1 \%)$ \\
Mild & $3(17.6 \%)$ & $22(30.5 \%)$ & $125(53.9 \%)$ \\
Moderate and severe & $14(82.4 \%)$ & $50(69.5 \%)$ &
\end{tabular}

Table 6. Clinical findings in children with familial Mediterranean fever according to different genotypes.

\begin{tabular}{|c|c|c|c|c|c|}
\hline & $\mathrm{M} 694 \mathrm{~V}^{*}(\mathrm{n}=89)$ & $\mathrm{E} 148 Q^{* *}(n=75)$ & ${\mathrm{V} 726 A^{* * *}}_{(n=68)}$ & Other $^{* * * *}(\mathbf{n}=\mathbf{8 9})$ & $P$-value \\
\hline Age of onset (years), mean \pm SD & $3.7 \pm 3.4$ & $4.7 \pm 3.4$ & $5.2 \pm 4$ & $4.8 \pm 3.6$ & 0.068 \\
\hline Age at diagnosis (years), mean \pm SD & $6.5 \pm 4.2$ & $7.0 \pm 3.8$ & $7.8 \pm 4.6$ & $7.0 \pm 4$ & 0.30 \\
\hline Delay in diagnosis (years), mean \pm SD & $2.8 \pm 2$ & $2.3 \pm 2$ & $2.7 \pm 2.5$ & $2.5 \pm 2$ & 0.69 \\
\hline Abdominal pain & $76(85.4 \%)$ & $64(85.3 \%)$ & $61(89.7 \%)$ & $71(79.8 \%)$ & 0.38 \\
\hline Fever & 79 (88.8\%) & $51(68 \%)$ & 57 (83.8\%) & $64(71.9 \%)$ & 0.003 \\
\hline Chest pain & $36(40.4 \%)$ & $13(17.3 \%)$ & $25(36.8 \%)$ & $24(27 \%)$ & 0.007 \\
\hline Arthralgia & $46(51.7 \%)$ & $31(41.3 \%)$ & 25 (36.8\%) & $36(40.4 \%)$ & 0.24 \\
\hline$>3$ hospitalizations prior to diagnosis & $4(4.5 \%)$ & $3(4 \%)$ & $4(5.9 \%)$ & $6(6.7 \%)$ & 0.78 \\
\hline Response to colchicine & & & & & 0.08 \\
\hline No response & $9(10.1 \%)$ & $11(14.6 \%)$ & 13 (19.1\%) & $23(25.8 \%)$ & \\
\hline Incomplete response & 47 (52.8\%) & $29(38.7 \%)$ & 29 (42.7\%) & 32 (36\%) & \\
\hline Complete response & 33 (37.1\%) & 35 (46.7\%) & $26(38.2 \%)$ & $34(38.2 \%)$ & \\
\hline Severity score & & & & & 0.005 \\
\hline Mild & 25 (28.1\%) & 28 (37.3\%) & $32(47.1 \%)$ & 47 (52.8\%) & \\
\hline Moderate and severe & 64 (71.9\%) & 47 (62.7\%) & 36 (52.9\%) & $42(47.2 \%)$ & \\
\hline
\end{tabular}

${ }^{*}$ M694V/M694V, M694V/Other or M694V/; ${ }^{* *}$ E148Q/E148Q, E148Q/Other or E148Q/; ${ }^{* * *}$ V726A/V726A, V726A/Other or V726A/; SD: standard deviation.

\section{Discussion}

The data in this study was obtained from the Laboratory Department of genetic testing at the Saint-Josef University that nearly all FMF suspected children in Lebanon were referred. Our study is the first that exclusively examine FMF children with positive $M E F V$ mutation in Lebanon. 
In our study, 56.4\% of FMF children were simple heterozygous. The possible explanation of this high rate of simple heterozyosity that give rise to FMF phenotype is the presence of one or more modifying alleles in other related genes, or other environmental factors. More recent study found a higher frequency of carriers for highly penetrant FMF mutations among patients with systemic inflammatory response syndrome and sepsis [8].

In our study, M694V was detected as the most common mutation (37.2\%) which is similar to almost all population except for Iraqis who witness a total absence of this allele [9]. In other various studies including Turks, the prevalence of M694V mutation was reported as 48\%, 52\%, 42\% and 71\% respectively [10]-[13]. E148Q is recognized to be the least penetrant mutation, and it has been more frequent in the healthy general population than in FMF patients, and some investigators look at it as "functional polymorphism "or as "sequence variant" [14] [15]. The most distinctive finding of the present study was the highest frequency of E148Q mutation, being the second most common mutation in FMF children. V726A was the third most frequent mutation, whereas, it is the second most common mutation seen in Armenian, Arabs, and Jews [9] [16] [17]. M680I is found mainly in Armenian and Arabs [11] [16]. In our study, M680I was the fourth most common mutation; similar to that reported in other Arab patients [9]. M694I was the fifth most common mutation in this study. Recent publications have shown that M694I was found mainly in Arabs, whereas it is less common in Turks and not found in Jews [18]. In an Egyptian study, among 66 patients, M694V was the most frequent allelic gene mutations followed by V726A then M680I (18.8\%, 17.4\% and 12.1\% respectively) [12]. In other studies conducted by both Touitou et al. and the Turkish FMF study group, the most common MEFV mutation in Turkey is M694V (57\% and 51\% respectively) followed by M680I (16.5\% and 14.4\% respectively) and V726A (13.9\% and 8.6\% respectively) [14] [19].

Most of the studies reported that FMF affect both sexes equally, with male or female predominance was also reported in different series [11] [20]. In our study, FMF affects both genders in a similar ratio. Regarding the child's parental origin of region and religion, FMF was more frequent in those originating from South Lebanon (44.9\%) and $87.2 \%$ of FMF children were of Moslem religion. This could be explained by the increase rate of consanguinity, gene frequency, and being derived from an ancient common ancestral population.

The onset of clinical manifestations in FMF occurs before 5 years of age in $63 \%$ - 68\% of cases and before 20 years of age in $90 \%$ of cases. However, the onset may be as early as 6 months of age [21]. In our study, 85\% of FMF children started to experience symptoms before 10 years of age which is similar to that reported in literature [22]. Upon comparing our study with pediatric FMF studies conducted in nearby countries, namely Syria [23], Egypt [24] and Turkey [25], our study population had age of onset much earlier than that reported in these studies (Table 6). This earlier age of onset that was observed in our study may be explained by the early detection of FMF patients, clarity of symptoms and the presence of family history of FMF (40.8\%).

Although fever is the symptom for which the disease is named, and although fever has been seen in $100 \%$ of patients in some reports, an incidence of only $80-85 \%$ has been observed in some studies [13] [26]. In our study the most common clinical symptom was abdominal pain, with fever being the second most common.

In our study, 8 of 321(2.5\%) patients underwent appendectomy, which was less than that reported by Talaat et al, who had 4 of 70 (5.7\%) FMF patients underwent appendectomy [27]. Settin et al. reported a higher percent of patients who underwent surgery; 15 of 66 (22.7\%) patients underwent laparotomy either for exploration or for appendectomy [24]. This could be the result of the severe abdominal pain associated with FMF in children that mimicked a surgical cause of that pain.

The percentage of colchicine non responders in this study (14.5\%) was higher than that reported in the other ethnic groups (5\% - 10\%) [28] [29]. This could be attributed to the noncompliance, inappropriate dosage and side effects of colchicine. These factors could affect the results of our study because we didn't monitor the compliance of our patients in routine clinical control visits and patients who missed doses of colchicine were not excluded. Also, it has been previously suggested that colchicine treatment failure is associated with decreased concentration of the drug in the mononuclear cells. Lidar et al suggested new findings that could be associated with colchicine treatment failure related to the difference in colchicine concentration in mononuclear cells (MNC) of the FMF patients. Lidar el al attributed this finding to the difference of activity of the P-glycoprotein (P-gp) efflux pump that is responsible for colchicine transport encoded by the MDR-1 gene which is an important modifier genetic factor that affects colchicine responsiveness, and as a result the course of the disease.

Studies conducted after the discovery of the gene (MEFV) related to FMF focused particularly on phenotypicgenotypic associations of this clinically heterogenic disease. Although results of these studies were sometimes confusing, they clarified that phenotypic-genotypic association of FMF is multifactorial and fairly complex. 
Studies pointed out those patients who are carriers of the M694V mutation have more severe phenotypic characteristics [16] [30]-[32]. Data from our study point toward an association between M694V and disease severity. When comparing patients according to M694V mutation, the M694V homozygous and heterozygous mutations have been shown together to have a moderate to severe disease activity $(P=0.02)$ in comparison with other/other group (Table 5). A recent study suggested that having a M694V mutation (for heterozygosity and homozygosity) increase the disease severity significantly in FMF children [33]. Homozygous M694V was shown to have increased frequency of joint affection, and rates of hospitalization than other groups (Table 5).

When comparing the groups according to different genotypes, moderate to severe disease was observed in M694V subgroup then followed by E148Q subgroup $(P=0.02)$, which was different than that reported in other studies that E148Q tend to have a mild clinical course [14]. This implies that E148Q is a disease-causing MEFV mutation as shown by Topaloglu et al. and most of who have this mutation are symptomatic and require treatment [31]. Clinical heterogeneity is observed in patients with E148Q mutation, ranging from absence of symptoms to severe symptoms [34]. This might be attributed to the presence of other genetic modifiers that may link to E148Q and which are as yet unknown may play a role in enhancing the expression of the disease. Besides E148Q mutation might have an up regulating effect on inflammation in both FMF and other chronic inflammatory processes. Thus, further prospective studies are required to empathize more the role of E148Q mutation in FMF.

In our study, there was no correlation between the response to colchicine and the different genotypes, however Oguz et al., established the relationship between M694V homozygosity and the unresponsiveness to colchicine treatment [25].

Since none of our patients developed amyloidosis, we could not conclude any association between M694V and the development of amyloidosis.

\section{Conclusion}

In conclusion, our study was the first to demonstrate the clinical features of childhood-onset Familial Mediterranean Fever (FMF), to define the frequency of mutation type, to assess genotype-phenotype correlation and the response to colchicine in FMF Lebanese children. This study established new aspects related to the spectrum of MEFV mutations and confirmed the mutational heterogeneity of FMF in Lebanon. The genotype distribution of FMF children in Lebanon was found to be different from other countries. The M694V is the most common mutation and seems to have an association with a more severe course and an earlier onset of the disease. On the other hand, E148Q was the second most common frequent mutation, and showed a relatively moderate disease severity.

Our study supports the mounting evidence that single heterozygotes may be associated with more severe FMF symptoms.

\section{References}

[1] Lidar, M. and Livneh, A. (2007) Familial Mediterranean Fever: Clinical, Molecular and Management Advancements. $J$ Med, 65, 318-324.

[2] Barakat, M.H., Kamik, A.M., Majeed, H.W., et al. (1968) Familial Mediterranean Fever (Recurrent Hereditary Polyserositis) in Arabs: A Study of 175 Patients and Review of the Literature. Q J Med, 60, 837-846.

[3] Ben-Chetrit, E. and Levy, M. (1998) Familial Mediterranean Fever. The Lancet, 351, 659-664. http://dx.doi.org/10.1016/S0140-6736(97)09408-7

[4] Özçakar, Z.B., et al. (2012) Why a New Diagnostic Criteria for Pediatric Familial Mediterranean fever Patients? Annals of Paediatric Rheumatology, 1, 207-213. http://dx.doi.org/10.5455/apr.121620121309

[5] Medlej-Hashim, M., Nehme, N., Chouery, E., Jalkh, N., et al. (2010) Novel MEFV Transcripts in Familial Mediterranean Fever Patients and Controls. BMC Medical Genetics, 11, 87. http://dx.doi.org/10.1186/1471-2350-11-87

[6] The French FMF Consortium (1997) A Candidate Gene for Familial Mediterranean Fever. Nature Genetics, 17, 25-31. http://dx.doi.org/10.1038/ng0997-25

[7] Ozen, S., Aktay, N., Lainka, E., et al. (2009) Disease Severity in Children and Adolescents with Familial Mediterranean Fever: A Comparative Study to Explore Environmental Effects on a Monogenic Disease. Annals of the Rheumatic Diseases, 68, 246-248. http://dx.doi.org/10.1136/ard.2008.092031

[8] Lachmann, H.J., Sengül, B., Yavuzşen, T.U., et al. (2006) Clinical and Subclinical Inflammation in Patients with Fa- 
milial Mediterranean Fever and in Heterozygous Carriers of MEFV Mutations. Rheumatology, 45, 746-750. http://dx.doi.org/10.1093/rheumatology/kei279

[9] Al-Alami, J.R., Tayeh, M.K., Najib, D.A., et al. (2003) Familial Mediterranean Fever Mutation Frequencies and Carrier Rates among a Mixed Arabic Population. Saudi Medical Journal, 24, 1055-1059.

[10] Yilmaz, E., Ozen, S., Balci, B., et al. (2001) Mutation Frequency of Familial Mediterranean Fever and Evidence for a High Carrier Rate in the Turkish Population. European Journal of Human Genetics, 9, 553-555. http://dx.doi.org/10.1038/sj.ejhg.5200674

[11] Yalcinkaya, F., Cakar, N., Misirlioglu, M., et al. (2000) Genotype-Phenotype Correlation in a Large Group of Turkish Patients with Familial Mediterranean Fever: Evidence for Mutation-Independent Amyloidosis. Rheumatology, 39, 67-72. http://dx.doi.org/10.1093/rheumatology/39.1.67

[12] Akar, N., Misiroglu, M., Yalcinkaya, F., et al. (2000) MEFV Mutations in Turkish Patients Suffering from Familial Mediterranean Fever. Human Mutation, 15, 118-119. http://dx.doi.org/10.1002/(SICI)1098-1004(200001)15:1<118::AID-HUMU29>3.0.CO;2-5

[13] Ertekin, V., Selimoglu, M.A. and Pirim, I. (2005) Familial Mediterranean Fever in a Childhood Population in Eastern Turkey. Pediatrics International, 47, 640-644. http://dx.doi.org/10.1111/j.1442-200x.2005.02140.x

[14] Touitou, I. (2001) The Spectrum of Familial Mediterranean Fever (FMF) Mutations. European Journal of Human Genetics, 9, 473-483. http://dx.doi.org/10.1038/sj.ejhg.5200658

[15] Ben-Chetrit, E., Lerer, I., Malamud, E., et al. (2000) The E148Q Mutation in the MEFV Gene: Is It a Disease-Causing Mutation or a Sequence Variant. Human Mutation, 15, 385-86. http://dx.doi.org/10.1002/(SICI)1098-1004(200004)15:4<385::AID-HUMU22>3.0.CO;2-A

[16] Cazeneuve, C., Sarkisian, T., Pecheux, C., et al. (1999) MEFV-Gene Analysis in Armenian Patients with Familial Mediterranean Fever: Diagnostic Value and Unfavorable Renal Prognosis of the M694V Homozygous Genotype-Genetic and Therapeutic Implications. American Journal of Human Genetics, 65, 88-97. http://dx.doi.org/10.1086/302459

[17] Padeh, S., Shinar, Y., Pras, E., et al. (2003) Clinical and Diagnostic Value of Genetic Testing in 216 Israeli Children with Familial Mediterranean Fever. The Journal of Rheumatology, 30, 185-190.

[18] Pras, M., Bronshpigel, N., Zemer, D. and Gafni, J. (1982) Variable Incidence of Amyloidosis in Familial Mediterranean Fever among Different Ethnic Groups. The Johns Hopkins Medical Journal, 150, 22-26.

[19] Cazeneuve, C., Ajrapetyan, H., Papin, S., et al. (2000) Identification of MEFV-Independent Modifying Genetic Factors for Familial Mediterranean Fever. American Journal of Human Genetics, 67, 1136-1143. http://dx.doi.org/10.1016/s0002-9297(07)62944-9

[20] Ben-Chetrit, E. and Touitou, I. (2009) Familial Mediterranean Fever in the World. Arthritis Care \& Research, 61, 1447-1453. http://dx.doi.org/10.1002/art.24458

[21] Gedalia, A. (2007) Hereditary Periodic Fever Syndrome. Nelson Textbook of Pediatrics. 18th Edition, 1800 Illustrations Saunders.

[22] Majeed, H.A., Rawashedeh, M., El-Shanti, H., Qubain, H., Khuri-Bulos, N. and Shahin, H.M. (1999) Familial Mediterranean Fever in Children: The Expanded Clinical Profile. QJM, 92, 309-318. http://dx.doi.org/10.1093/qjmed/92.6.309

[23] Jarjour, R.A. (2010) Familial Mediterranean Fever in Syria Patients: MEFV Gene Mutations and Genotype -Phenotype Correlation. Molecular Biology Reports, 37, 1-5. http://dx.doi.org/10.1007/s11033-009-9475-9

[24] Settin, A., El-Baz, R., Abd Rasool, M., et al. (2007) Clinical and Molecular Diagnosis of Familial Mediterranean Fever in Egyptian Children. Journal of Gastrointestinal and Liver Diseases, 16, 141-145.

[25] Soylemezoglu, O., Argar, M., Fidan, K., Gonen, S., et al. (2009) Unresponsiveness to Colchicine Therapy in Patients with Familial Mediterranean Fever Homozygous for the M694V Mutation. Journal of Rheumatology, 37, 182-189. http://dx.doi.org/10.3899/jrheum.090273

[26] Samli, H., Dogru, O., Bukulmez, A., Yuksel, E., Ovali, F. and Solak, M. (2006) Relationship of Tel Hashomer Criteria and Mediterranean Fever Gene Mutations in a Cohort of Turkish familial Mediterranean Fever Patients. Saudi Medical Journal, 27, 1822-1826.

[27] Talaat, H.S., Mohamed, M.F., El Rifai, N.M. and Gomaa, M.A. (2012) The Expanded Clinical Profile and Efficacy of Colchicine Therapy in Egyptian Children Suffering from Familial Mediterranean Fever: A Descriptive Study. Italian Journal of Pediatric, 38, 66. http://dx.doi.org/10.1186/1824-7288-38-66

[28] Ben-Chetrit, E. and Levy, M. (1998) Familial Mediterranean Fever. The Lancet, 351, 659-664. http://dx.doi.org/10.1016/S0140-6736(97)09408-7

[29] Onen, F. (2005) Familial Mediterranean Fever. Rheumatology International, 26, 489-496. http://dx.doi.org/10.1007/s00296-005-0074-3 
[30] Yilmaz, R., Ozer, S., Ozyurt, H., Erkorkmaz, U. and Sahin, S. (2009) Familial Mediterranean Fever Gene Mutations in the Inner Northern Region of Turkey and Genotype-Phenotype Correlation in Children. Journal of Pediatrics and Child Health, 45, 641-645. http://dx.doi.org/10.1111/j.1440-1754.2009.01587.x

[31] Shohat, M., Magal, N., Shohat, T., et al. (1999) Phenotype-Genotype Correlation in Familial Mediterranean Fever: Evidence for an Association between Met694Val and Amyloidosis. European Journal of Human Genetics, 7, $287-292$. http://dx.doi.org/10.1038/sj.ejhg.5200303

[32] Livneh, A., Langevitz, P., Shinar, Y., et al. (1999) MEFV Mutation Analysis in Patients Suffering from Amyloidosis of Familial Mediterranean Fever. Amyloid, 6, 1-6. http://dx.doi.org/10.3109/13506129908993281

[33] Ozen, S., Demirkaya, E., Amaryan, G., et al. (2013) Results from a Multicenter International Registry of Familial Mediterranean Fever: Impact of Environment on the Expression of a Monogenic Disease in Children. Annals of the Rheumatic Diseases, 73, 662-667. http://dx.doi.org/10.1136/annrheumdis-2012-202708

[34] Ozen, S., Besbas, N., Bakkaloglu, A. and Yilmaz, E. (2002) Q148 Mutation and Familial Mediterranean Fever. QJM, 95, 332-333. http://dx.doi.org/10.1093/qjmed/95.5.332

\section{Submit or recommend next manuscript to SCIRP and we will provide best service for you:}

Accepting pre-submission inquiries through Email, Facebook, LinkedIn, Twitter, etc.

A wide selection of journals (inclusive of 9 subjects, more than 200 journals)

Providing 24-hour high-quality service

User-friendly online submission system

Fair and swift peer-review system

Efficient typesetting and proofreading procedure

Display of the result of downloads and visits, as well as the number of cited articles

Maximum dissemination of your research work

Submit your manuscript at: http://papersubmission.scirp.org/ 